\title{
Nuevas cabeceras contra viejos señoríos: la separación de Tecomatlan del señorío de Yanhuitlan
}

\author{
Manuel A. Hermann Lejarazu \\ Centro de Investigaciones y Estudios Superiores \\ en Antropología Social, (CIESAS), México
}

En el año de 1582, el pueblo de Tecomatlan presentaba antes las instancias virreinales una serie de testimonios para probar su independencia del entonces más importante y poderoso señorío de la Mixteca Alta: Yanhuitlan. Según las autoridades de Tecomatlan, este pueblo había tenido su cacique y "señor natural" desde la época prehispánica y no quería reconocer al pueblo de Yanhuitlan como su cabecera debido, principalmente, a la reorganización colonial implementada después de la conquista española.

Palabras Clave: Mixteca, señoríos, cabeceras, sujetos, Yanhuitlan, Tecomatlan.

In 1582 the town of Tecomatlan attempted to prove its independence from the most important and powerful lordship of the Mixteca Alta: Yanhuitlan. According to the Tecomatlan autority, this town had had its own "cacique" $y$ "señor natural" since prehispanic times. Tecomatlan denied the roll of Yanhuitlan as "cabecera" or colonial administrative center due to colonial reorganization after to the Spanish Conquest.

KeYwords: Mixteca, Lordships, Head towns, Hamlets, Yanhuitlan, Tecomatlan.

\section{Introducción}

De las diversas regiones que conformaron el mundo mesoamericano antes de la llegada de los españoles, existe aún hoy en día una extensa zona ubicada al sur de México que se conoce como la Mixteca. Esta región, conformada en su mayor parte por extensas cadenas montañosas, ocupa geográficamente un punto de enlace entre las amplias planicies del centro de México y las fajas costeras de Centroamérica, lo que la constituyó como un área en la que floreció un gran dinamismo cultural que dejó sentir su influencia en varias partes del México prehispánico.

Hasta hace relativamente poco tiempo, la Mixteca era un territorio casi desconocido para historiadores, antropólogos o lingüistas pero, afortu- 
nadamente, este panorama ha cambiado en años recientes y cada día son más los estudios dedicados al pasado de esta región.

En términos generales, podemos decir que actualmente el período histórico mejor documentado es el cercano a la conquista española (alrededor de los siglos XV y XVI). Pero gracias a otras disciplinas, como la arqueología, se ha determinado la antigüedad de la cultura Mixteca hasta poco más de un milenio antes de Cristo. ${ }^{1}$ No obstante, el hecho de que exista una mayor información para la época que hemos señalado no significa que tengamos un panorama completo sobre la situación social, política o cultural de los diversos pueblos que ocuparon esta parte del sur de México.

Efectivamente, es necesario mencionar que son muy escasas las fuentes de que disponemos para poder realizar estudios a fondo sobre el pasado mixteco. No hay para esta región alguna crónica, historia o tratado que pudiera compararse con la obra de un fray Bernardino de Sahagún para los nahuas o de un fray Diego de Landa para los mayas. Pero aunque no haya nada parecido para la Mixteca, paradójicamente, de aquí procede el único corpus de documentos prehispánicos originados por los propios pueblos mixtecos antes de la llegada de los españoles. Nos referimos a los códices o manuscritos pictóricos que constituyen un conjunto de fuentes de primera mano que nos aportan suficiente información que, en buena medida, sustituye la carencia de escritos de otra índole. ${ }^{2}$

Por otro lado, también existen otros textos, igualmente valiosos, que aportan un sinnúmero de datos para la historia mixteca. Nos referimos a los documentos generados por la administración española durante los tres siglos de dominación virreinal. Muchos de estos documentos escritos en los despachos de Cabildos, Alcaldías, Audiencias y hasta en la corte real, han sido aprovechados por los historiadores como otro grupo de fuentes para acercarse al pasado indígena mixteco. Es precisamente a través del análisis de estos documentos jurídicos, con el que abordaremos el presente estudio dedicado al impacto que representó para la sociedad indígena colonial la implementación de nuevas formas de organización traídas por el mundo europeo.

1 Spores, Ronald: The Mixtecs in Ancient and Colonial Times, University of Oklahoma Press, Norman, 1984, págs. 13 y 18.

2 Los códices mixtecos prehispánicos se conocen bajo los siguientes nombres: Códice Nuttall, Códice Colombino, Códice Becker 1, Códice Vindobonensis, Códice Bodley y Códice Selden. La bibliografía sobre códices mixtecos es extensa pero podemos citar a Smith, Mary Elizabeth: Picture Writing from Ancient Southern Mexico: Mixtec Place Signs and Maps, University of Oklahoma Press, Norman, 1973. 
El caso concreto que trataremos aquí versa sobre los intentos de una comunidad mixteca llamada Tecomatlan para separarse jurídica y políticamente de una población mayor que funcionaba como cabecera de toda una extensa región: Yanhuitlan.

\section{Yanhuitlan antes y después de la conquista}

Dentro de la literatura sobre los estudios de la Mixteca es bien conocida la importancia y preeminencia que alcanzó el señorío de Yanhuitlan durante el siglo XVI, pues, según nos mencionan algunas fuentes y documentos, llegó a ser una de las más poderosas comunidades de la Mixteca Alta tanto en los años anteriores a la conquista, como en los que la siguieron. Sin embargo, son muy escasos los datos con que contamos actualmente para poder reconstruir la historia prehispánica de este lugar, así como también desconocemos las causas que llevaron al surgimiento de Yanhuitlan como centro rector al momento de la llegada de los conquistadores.

Debido a que no sobrevivió ningún códice prehispánico elaborado en este lugar, no tenemos tampoco la certeza sobre los nombres de los señores que gobernaron aquí, por lo que únicamente contamos con escasas referencias sobre Yanhuitlan en otros códices o documentos pictográficos para poder rescatar alguna información referida a su historia antigua.

Por el contrario, de la etapa colonial temprana provienen numerosos datos que señalan a Yanhuitlan como la cabecera principal del extenso valle de Nochixtlan con un número elevado de poblaciones sujetas (alrededor de dieciséis) aunque, de acuerdo con otros documentos, la cifra sobre el total de estancias que le pertenecían llegó a variar durante el primer siglo de presencia española.

A lo largo del siglo XVI, Yanhuitlan se mantuvo como uno de los principales centros políticos y económicos de la Mixteca Alta debido, entre otras razones, a la pujante industria de la seda que fue introducida en la región de manera indirecta por Hernán Cortés. ${ }^{3}$ Pero no únicamente la sericultura le dio a Yanhuitlan una gran prosperidad económica, sino que también sobrevivió a la conquista española el cultivo de la grana cochinilla, un pequeño insecto criado en una variedad de nopal, que produce un coloran-

3 Cortés le entregó a María de Aguilar, esposa de su primo Francisco de las Casas y primer encomendero de Yanhuitlan, la semilla del gusano para implementar su cultivo. Ver la obra de Spores, Ronald: The Mixtec Kings and their People, University of Oklahoma Press, Norman, 1967, pág. 81. 
te rojo para teñir telas. La importancia de la grana mixteca fue de tal magnitud que existen referencias de su gran producción en textos y crónicas de la época. ${ }^{4}$

De alguna manera podemos pensar que este importante auge económico de Yanhuitlan tuvo su base o cimientos en las antiguas estructuras políticas de la época prehispánica. Es decir, estamos pensando, sobre todo, en la inmensa fuerza de trabajo que se requirió para que aquellas industrias prosperaran. Si bien es cierto que tanto los encomenderos como los frailes dominicos intervinieron en la enseñanza de las técnicas de la sericultura, todo ello no hubiera sido posible, quizá, sin el gran poder de convocatoria que tenían los antiguos señores de raigambre prehispánica sobre numerosas poblaciones mixtecas. En efecto, los caciques de Yanhuitlan aún conservaban mucho de su poder hacia la segunda mitad del siglo XVI, pues no solamente controlaban a la población que se encontraba dentro de su propia comunidad, sino también a la que pertenecía a sus pueblos sujetos.

No obstante, la antigua situación política ya estaba cambiando con respecto a la época prehispánica, pues diversas comunidades que habían estado subordinadas a Yanhuitlan durante décadas, pronto comenzaron a separarse de ella para cambiar radicalmente su posición jurídica ante los nuevos dominadores.

\section{La relación cabecera-sujeto}

No es desconocido para nosotros el gran impacto que representó para la sociedad indígena mesoamericana el reordenamiento jurídico y territorial que implantó la Corona española apenas unos años después de consumada la conquista. En varias regiones del centro de México, por ejemplo, la desarticulación paulatina del señorío indígena fue una de las políticas constantes en beneficio del fortalecimiento de la institución del Cabildo introducida por el nuevo orden. ${ }^{5}$ Sin embargo, sabemos que para la Mixteca este proceso de sustitución de la figura del señor local pasó por una transición mucho más lenta que en otras partes, al grado de que hubo una verdadera coexistencia, durante un tiempo prolongado, de la figura del cacique Nochixtlan.

4 Ibídem, pág. 83. Otras comunidades mixtecas también florecieron con la cochinilla como

5 Entre algunos textos que abordan este tema podemos citar a Menegus Borneman, Margarita: Del señorío indígena a la república de indios. El caso de Toluca, 1500-1600, Consejo Nacional para la Cultura y las Artes, México, 1994. 
y el Cabildo indígena, pues incluso el propio cacique ocupó en diversas ocasiones el cargo de gobernador en la nueva institución. ${ }^{6}$

No obstante, los efectos de la reorganización colonial iban a dejarse sentir en otras esferas de la estructura sociopolítica de las antiguas comunidades mixtecas. Nos referimos, en concreto, a los cambios suscitados entre la relación cabecera-sujeto hacia fines del siglo XVI en la Mixteca Alta, lo que constituyó un desequilibrio político y territorial entre numerosos pueblos.

De acuerdo con los datos provenientes de diversos documentos, algunas comunidades sujetas comenzaron a poner en entredicho el papel hegemónico de algunos pueblos-cabecera desde 1552. En los siglos subsecuentes, lograrían su separación definitiva. Por ejemplo, a finales del siglo XVII, el pueblo de San Francisco Chindúa buscó independizarse de la cabecera de Yanhuitlan; ${ }^{7}$ y, en 1796, hizo lo mismo el pueblo de San Pedro Quilitongo. ${ }^{8}$ Comunidades que, al menos por dos siglos, habían estado sujetas al poderoso señorío. De esta manera, muchas comunidades indígenas buscaron alcanzar el estatus de cabecera independiente desde mediados del siglo XVI en adelante. ${ }^{9}$ Kevin Terraciano propone que esta desestabilización del reordenamiento español fue una respuesta indígena a la imposición de un modelo estático y jerárquico que no existía en una etapa anterior a la conquista. ${ }^{10}$

Como era de esperarse, esta situación afectó no sólo al señorío de Yanhuitlan sino también a otras cabeceras que, con el paso del tiempo, fueron perdiendo jurisdicción y recursos económicos de los que habían sido sus pueblos sujetos.

El volumen 162 de la sección Escribanía de Cámara del Archivo General de Indias en Sevilla contiene un muy interesante y complejo proceso sobre la separación del pueblo de Tecomatlan de la cabecera de Yanhuitlan hacia 1582, por lo que constituye un buen ejemplo sobre los conflictos nacientes en la aún joven vida colonial indígena.

6 Pastor, Rodolfo: Campesinos y Reformas: La Mixteca, 1700-1856, El Colegio de México, México, 1987, págs. 80-82. Hermann Lejarazu, Manuel A.: "Genealogías gobernantes y transformación política en un cacicazgo mixteco: el Códice de San Pedro Cántaros Coxcaltepec", en GonzálezHermosillo, Francisco (Coord.): Gobierno y economía en los pueblos indios del México colonial, Instituto Nacional de Antropología e Historia, México, 2001, págs. 61-73.

7 Archivo General de la Nación (en adelante AGN), Indios, 36, 114.

8 Ibídem, Indios, 70, 88.

9 Terraciano, Kevin: "The Colonial Mixtec Community", Hispanic American Historical Review, 80-1, Duke,February, 2000, págs. 1-42, pág. 13.

10 Ibídem, pág. 12. 


\section{El pleito sobre la separación de Tecomatlan}

Como mencionamos, en el año de 1582 el pueblo de Tecomatlan presentaba ante las instancias virreinales una serie de testimonios para comprobar su independencia de Yanhuitlan. Según las autoridades de Tecomatlan, este pueblo había tenido su cacique y "señor natural" desde la época prehispánica, por lo que no reconocía al pueblo de Yanhuitlan como su cabecera. De acuerdo con las autoridades o "principales" de Tecomatlan, su antiguo señor llevaba el nombre de "Matlaze yztli", hijo de Navi Calzin, quien fuera rey y cacique de toda la Mixteca Alta y Baja, y nunca habían entregado tributo al pueblo de Yanhuitlan ni a ningún otro. Según mencionaban, Tecomatlan había sido cabecera en el momento de la conquista y lo que hizo la reorganización española fue darlo en encomienda, junto con Yanhuitlan, a Francisco de las Casas, pero, de acuerdo a los testimonios de Tecomatlan, el pueblo nunca fue estancia sujeta a la cabecera de Yanhuitlan.

Por otro lado, los de Yanhuitlan argumentaban que el pueblo de Tecomatlan estaba asentado y situado dentro de sus propios términos y jurisdicción desde que se había fundado el pueblo y que de "tiempo inmemorial, en tiempo de su infidelidad, los indios de Tecomatlan han estado sujetos al señorío, justicia, voluntad y mando del pueblo de Yanhuitlan". ${ }^{11}$

El documento que analizamos menciona:

Los de yanhuitlan dicen que de tiempo inmemorial, El cacique, justicia y regimiento de yanhuitlán ha elegido y nombrado persona que asista como principal al dicho pueblo de tecomatlán para los negocios menudos que se ofrecen, la cual persona y mandon que iba y estaba en el dicho pueblo de tecomatlán era sujeto y obediente al cacique y justicia de yanhuitlán y en la dicha estancia nunca hubo otro señorio ni cacicazgo sino este. ${ }^{12}$

A lo largo de este proceso, ambas partes presentaron una serie de testigos para dar crédito a los diferentes argumentos que se esgrimían para la resolución de este conflicto. Un interesante testimonio a favor de Yanhuitlan lo expresa un fraile dominico residente en el convento, llamado Francisco de Luyando, quien contesta en el interrogatorio lo siguiente:

11 Archivo General de Indias (en adelante AGI), Escribanía de Cámara, 162, 67 r. y v.

12 Ibídem, 67 v. 
A la sesta pregunta dijo: que lo que de ella sabe es que este testigo ha visto muchas veces las pinturas antiguas que tiene el dicho pueblo de Yanhuitlán a las quales se da toda fee y credicto porque como no sea contra la fee católica y contra las leyes del reino se guarda e cumple lo que en ellas se contiene, por razón que en tiempo de su infidelidad no tenían los dichos naturales otro modo de escritura y ansi las tienen e guardan en presente de mucho recaudo y por ellas consta y parece que la dicha estancia de Tecomatllán está dentro de los términos del dicho pueblo de Yanhuitlán y como tal subjeto a él y en las dichas pinturas tienen puesta la descendencia de los caciques que han sido en el dicho pueblo de Yanhuitlán e sus subjetos hasta venir a dar en don Gabriel de Guzmán que a el presente es gobernador e cacique del dicho pueblo de Yanhuitlán y estancia de Tecomatlán y los demás subjetos. ${ }^{13}$

Un español avecindado en Yanhuitlan, de apellido Velásquez, dijo:

...en los cuarenta y seis años que vive en el pueblo de yanhuitlan sabe que la dicha estancia de tecomatlan siempre la a tenido e tiene por estancia sujeta a el dicho pueblo de yanhuitlan y como tal su sujeta a el todos los principales tequitatos y mandones los a visto recoger el tributo y llevallo y entregallo al cacique, gobernador y alcaldes e regidores del dicho pueblo y cabecera de yanhuitlan. ${ }^{14}$

A este interesante comentario se suma el de, por ejemplo, Domingo Ramírez, principal del pueblo de Patlaystlahuaca, hoy Yodo Cono de Porfirio Díaz:

A la sesta pregunta dijo: que ha visto las pinturas antiguas que el dicho pueblo de yanhuitlan tiene a las quales se da fee y credicto y como tales las tienen y guardan en el archivo e caja de la comunidad del dicho pueblo...en las quales está pintado y señalado con cuenta y razón en lengua y señales de caracteres los caciques y señores que ha habido en el dicho pueblo de yanhuitlan que son los veinticuatro que la pregunta dice hasta venir a dar en don gabriel de guzman cacique e gobernador que a el presente es de dicho pueblo. ${ }^{15}$

Sin duda, estos testimonios recopilados del documento que estamos trabajando hacen una tenaz defensa del señorío de Yanhuitlan y lo ubican como una cabecera dotada de plenos derechos de dominio desde la época prehispánica hasta el momento de la conquista. Sin duda, de especial interés es la referencia a un manuscrito pictográfico o códice que dicen numerosos testigos haber visto en la comunidad de Yanhuitlan y cuya validez jurídica no se ponía en duda durante los procesos legales ante las instancias virreinales. Desafortunadamente, hoy en día este manuscrito ha desapare-

13 Ibídem, 98 v. y 99 r.

14 Ibídem, $101 \mathrm{v}$.

15 Ibídem, 106 r. y v. 
cido y no existe ningún códice en el pueblo de Yanhuitlan, ni tampoco hay noticias de él en ningún repositorio de México o del extranjero. Pero lo importante es señalar aquí, cómo hacia la segunda mitad del siglo XVI los códices seguían constituyendo un documento legal para acudir a ellos en los pleitos y litigios que se suscitaron durante el período colonial. ${ }^{16}$

Mary Elizabeth Smith plantea la posibilidad de que el Códice Selden, un manuscrito pictórico proveniente del pueblo de Jaltepec, fue elaborado como evidencia durante el litigio que sostuvieron el propio Jaltepec y Yanhuitlan por la posesión de una estancia sujeta llamada Zahuatlan. ${ }^{17}$ Todo ello nos indica sobre el valor jurídico que los códices seguían teniendo en una etapa avanzada de régimen colonial. Por ejemplo, Diego de Guzmán, quien se nombraba como cacique de Tecomatlan, no presenta códices para comprobar su descendencia de Matlace yztli, por lo que esto le restó credibilidad a la hora de la reunión de pruebas. Entre paréntesis podemos mencionar que el nombre náhuatl Matlace iztli, puede referirse al nombre calendárico de 10-Pedernal, entendiendo el vocablo Matlactli, 10 y el nombre yztly de itztli, obsidiana, navaja de obsidiana, como una referencia al nombre Pedernal.

Pero como quiera que sea, no hay referencias en los códices prehispánicos de algún personaje que se pudiera relacionar con este nombre ni con el del personaje Navi Calzin, o Nahui Calli, 4-Casa, por lo que su identificación en otros contextos es incierta.

No obstante, a pesar de la importancia de los códices como instrumento jurídico, es pertinente la observación de Terraciano acerca de que los códices expresaban el punto de vista del pueblo que los había realizado, lo que hacía difícil la resolución de algún conflicto por parte de la administración española. ${ }^{18}$

16 Es necesario aclarar que si bien existe un documento que actualmente se denomina Códice de Yanhuitlan, no es de ninguna manera el mismo manuscrito al que el pleito legal hace referencia. Ya que claramente se menciona en el proceso que dicha "pintura" registraba una larga y extensa genealogía de los señores que habían gobernado en Yanhuitlan desde la época prehispánica, y el códice que existe actualmente con este nombre, carece de una lista genealógica y es poco probable que la haya tenido alguna vez a pesar de ser un documento incompleto.

17 Smith, Mary Elizabeth: "Why the Second Codex Selden was Painted", en Marcus, Joyce y Zeitlin, Judith Francis (eds.): Caciques and their People. A Volume in Honor of Ronald Spores, University of Michigan, Ann Arbor, Michigan, 1994, págs. 124-126. Según menciona esta autora, la disputa entre Jaltepec y Yanhuitlan por la posesión de la estancia sujeta de Zahuatlan se encuentra documentada hacia 1539.

18 Terraciano, Kevin: The Mixtecs of Colonial Oaxaca. Nudzahui History, Sixteenth through Eighteenth Centuries, Stanford University Press, Stanford, California, 2001, pág. 129. 


\section{Los argumentos jurídicos}

Pero continuando con el proceso entre Tecomatlan y Yanhuitlan, los testigos presentados por Yanhuitlan mencionaron en reiteradas ocasiones cómo el gobernador y alcaldes de Yanhuitlan iban a la estancia de Tecomatlan a impartir justicia, pues este pueblo como estancia o sujeto no podía elegir sus propias autoridades para determinar o sentenciar en pleitos civiles y criminales, ya que estas facultades sólo podían ser ejecutadas por el gobernador y cacique de Yanhuitlan junto con los oficiales de república.

Un anciano mixteco del pueblo de Soyaltepec testificó lo siguiente:

A la quarta pregunta dijo: que lo que della sabe es que del dicho tiempo que a declarado se acuerda siempre ha visto este testigo que la dicha estancia de tecomatlan e naturales della an estado subjetos del mando voluntad e señorio del dicho pueblo de Yanhuitlan e regimiento de los quales siempre ha visto yr a la dicha estancia de tecomatlan y en ella conocer de los casos y cosas pleitos ceviles y criminales castigando y siempre porque este testigo estando en la dicha estancia lo ha visto y en tiempo de su ynfidilidad se hacia y usava acudiendo siempre a la dicha su cabecera con los casos y cosas que habia que detiminar e sentenciar. ${ }^{19}$

Lo interesante de estos testimonios es que los de Yanhuitlan querían dejar en claro que desde la época prehispánica ellos tenían plena jurisdicción sobre el pueblo de Tecomatlan, sólo que ahora empleaban ya el sistema político implantado por la Corona y ejerciendo plenamente el derecho de mando en la relación cabecera-sujeto. Sin embargo, nos llama la atención si efectivamente esto sucedía en la época prehispánica, como argumentaban los de Yanhuitlan, o si no era acaso una adaptación del sistema español proyectándolo hacia el pasado pero ajustándose a la nueva realidad jurídica imperante en el siglo XVI colonial.

Varios datos sobre formas de gobierno e impartición de justicia en los pueblos indígenas antes de la conquista se encuentran en las relaciones geográficas del XVI. Por ejemplo, la relación geográfica de Juxtlahuaca y Tecomaxtlahuaca menciona que los caciques o señores naturales eran los que mandaban y castigaban los delitos que entre ellos sucedían. ${ }^{20}$

19 AGI, Escribanía de Cámara, 162, 120 r.

20 Acuña, René (editor): Relaciones Geográficas del siglo XVI: Antequera, t. 1, Universidad Nacional Autónoma de México, México, 1984, págs. 286 y 287. 
La relación geográfica de Mixtepec señala que ellos dependían del cacique de Tlaxiaco, quien era el que mandaba y castigaba los delitos que entre ellos se averiguaban. ${ }^{21}$

Esta información coincide con la relación de Xicayan, ya que menciona que también existía un señor que gobernaba en la región, pero cuando había que resolver algún asunto jurídico tenía que consultar a cuatro principales de origen nahuatl que vivían en el pueblo en una guarnición o avanzada dependiente del Tlahtoani mexica. ${ }^{22}$

Finalmente, la relación de Guaxilotitlan señala que el señor natural era el que gobernaba y mandaba en la comunidad, hacía justicia en los pleitos y nombraba en cada barrio y estancia un tequitlato, el cual tenía cargo de los habitantes del barrio o estancia. Recogía los tributos y daba noticias de los delitos y pleitos al cacique para que éste los resolviera..$^{23}$

De manera notable, la información de la relación de Guaxilotitlan coincide con los testimonios presentados por el señorío de Yanhuitlan, ya que éstos argumentaban que

...de tiempo inmemorial el cacique, justicia y regimiento han elegido y nombrado persona que asista como principal al pueblo de tecomatlan para los negocios menudos que se ofrecen, la cual persona y mandón que iba y estaba en el dicho pueblo de tecomatlan era sujeto y obediente al cacique y justicia de yanhuitlan. ${ }^{24}$

Por su parte, el español Velásquez menciona:

...sabe que la dicha estancia de tecomatlan siempre la ha tenido y tiene por estancia sujeta a el dicho pueblo de Yanhuitlán y como tal sujeta a el todos los principales tequitlatos y mandones los ha visto recoger el tributo y llevallo y entregallo al cacique, gobernador y alcaldes y regidores del dicho pueblo y cabecera de yanhuitlan. ${ }^{25}$

A manera de comparación, por ejemplo, sabemos que el sistema de recaudación nahua funcionaba precisamente con el nombramiento de calpixques y tequitlatos que designaba directamente el Tlahtoani para recoger el tributo en los pueblos dependientes del estado mexica. Por lo que en el fondo tenemos un sistema económico y jurídico de origen prehispánico.

Con los datos encontrados para la región mixteca, vemos que este sistema funcionaba de manera similar en los señoríos de cierta importancia y

21 Ibídem, pág. 293.

22 Ibídem, pág. 307.

23 Ibídem, pág. 215.

24 AGI, Escribanía de Cámara, 162, 167 v.

25 Ibídem, $101 \mathrm{v}$. 
extensión. El señorío de Yanhuitlan era, sin duda, el de mayor poder en la Mixteca, por lo que debió efectivamente hacer uso de un sistema de recaudación quizá tomado del modelo mexica.

\section{El reordenamiento colonial}

Kevin Terraciano señala que varios Yuhuitayu (nombre mixteco de las poblaciones en las que residía una pareja de gobernantes descendiente de un linaje importante) se vieron favorecidos por el reordenamiento colonial al ser colocados como pueblos cabeceras de otros yuhuitayu más pequeños que no habían estado, efectivamente, bajo el control de algún señorío en la época prehispánica. ${ }^{26}$

Algunos de los menos prominentes yuhuitayu у п̃uи (poblaciones en las que residía una pareja de gobernantes pero quizá de menor rango que aquéllas de linaje importante) fueron relegados al estatus de sujeto.

Terraciano menciona atinadamente que don Diego de Guzmán, medio hermano de don Gabriel de Guzmán, cacique de Yanhuitlan, pretendió ser cacique de Tecomatlan e independizarse de su cabecera al momento de contraer matrimonio con una mujer que provenía de un linaje real o importante, hecho que automáticamente lo convertía en gobernante de un nuevo yuhuitayu. ${ }^{27}$

Al parecer, entonces, don Diego apelaba a las antiguas costumbres prehispánicas en las que no existía una división tan tajante entre poblaciones rectoras y subordinadas y en las que el principio de descendencia real por línea patrilineal y matrilineal era lo que determinaba el estatus de un yuhuitayu. Terraciano menciona también que las disputas entre los pueblos por alcanzar el rango de yuhuitayu indudablemente existieron antes de la conquista, pero el nuevo orden colonial español concedió indebidas ventajas sólo a algunos lugares prominentes por la exclusión de otros. ${ }^{28}$

Si bien, en general, estamos completamente de acuerdo con el análisis de Terraciano, hay al menos (en lo que se refiere en concreto al proceso que nos ocupa) algunos indicios en los testimonios de Yanhuitlán que me hacen pensar en cierta subordinación que efectivamente existió por parte de Tecomatlán al momento de la llegada de los conquistadores. Es decir,

26 Terraciano: The Mixtecs of Colonial Oaxaca..., pág. 121.

27 Ibídem, pág. 127.

28 Ibídem, pág. 129. 
coincidimos con aquel autor en que el orden colonial trastocó las antiguas formas de organización prehispánica e implementó un sistema más acorde a un tipo de administración europea. No obstante, nos gustaría vislumbrar la posibilidad de que existieron ciertas relaciones jerárquicas entre Yanhuitlán y Tecomatlán en la época prehispánica, que reflejan las dinámicas de interacción social y política que debe haberse dado entre señores de un linaje principal con los de la nobleza secundaria.

Un testimonio de un personaje noble del importante pueblo de Tilantongo ofrece esclarecedores datos sobre las relaciones de jerarquía que existieron en la época prehispánica entre señores de diferente estatus en situaciones particulares como la guerra:

Domingo Hernández, de 65 años:

...vio a la estancia de tecomatlan como sujeta en tiempo que se conquistaba esta mixteca por los mexicanos porque en aquel tiempo su padre de este testigo fue uno de los capitanes nombrados para la dicha guerra y este testigo como mozo yva con el y llegaron a la dicha estancia de tecomatlan a sacar gente y enbiaron a algunos indios con la dicha embajada a el pueblo de yanhuitlan como a cabecera de la dicha estancia para que della y de las demás a el subjetas les diesen gente contra los dichos mexicanos y aquella sazon hera cacique y señor del dicho yanhuitlan un yndio que se nombraba ya quese que estava infiel y este enbio a decir a el principal questava en la dicha estancia que les faboreciese y diesen la gente que de guerra uviese y ansi el dicho principal que en la dicha estancia que se nombraba qu huyo se la dio y se fueron en su viaje... ${ }^{29}$

Como podemos apreciar, un testimonio de esta naturaleza señala varios aspectos interesantes sobre las antiguas relaciones políticas entre las antiguas comunidades mixtecas. En concreto, el señor de Yanhuitlan solicita el apoyo logístico y militar de sus pueblos subordinados para reclutar gente que le ayude en la guerra contra la invasión mexica.

Un testimonio de otra naturaleza reitera el papel que tenía Tecomatlan con respecto a Yanhuitlan. En este caso, un antiguo sacerdote habla sobre las ofrendas que se entregaban para realizar los cultos:

A la tercera pregunta dijo...por si mismo vio que antes que se ganase la tierra y viniese el marques del valle a ella venyan (a Yanhuitlán) los naturales que había en la dicha estancia de tecomatlan a la cabecera de yanhuitlan a traer para los sacrificios e ydolatrias que en aquel tiempo los naturales usavan a traer y trayan palomas, codornices y otras cosas semejantes que si no fueran tales subjetos no acudieran como acudian con ello todo. ${ }^{30}$

29 AGI, Escribanía de Cámara, 162, 165 r.

30 Ibídem, 119 v. 


\section{Conclusiones}

Aunque estos son solamente algunos ejemplos, pues habría que revisar mayor documentación de otros lugares, pienso que sí debieron haber existido ciertas relaciones de desigualdad entre algunas poblaciones de diferente estatus, por lo que tal vez, para el caso que estamos tratando, Tecomatlan pudo haber sido subordinada a Yanhuitlan. Desde luego, no podemos soslayar el hecho de que el pueblo de Yanhuitlan ya ejercía plenamente sus derechos como pueblo-cabecera hacia 1582 pero, al parecer, efectivamente no hay indicios de que el pueblo de Tecomatlan hubiera estado independiente en el momento de la conquista.

Sabemos, por otro lado, según menciona Terraciano, que efectivamente algunas comunidades que llegaron a ser yuhuitayu antes de la conquista (como Yucuita y Chachoapan) fueron relegadas a estancias sujetas de Yanhuitlan tras la reorganización colonial. Pero, también es verdad que no todas esas comunidades llegaron tener una jerarquía similar entre sí.

Según la documentación hasta el momento analizada, Yanhuitlan ya ejercía sus plenos derechos como cabecera dentro del esquema político y jurídico español, lo que demuestra una completa adaptación a la reorganización española después de la conquista. Es verdad también que, a lo largo del proceso, se emplea en los interrogatorios una serie de anacronismos e inconsistencias que reflejaban el orden español; ${ }^{31}$ pero es evidente, al mismo tiempo, que en las respuestas proporcionadas por nobles y principales indígenas subyace también información que difícilmente haya provenido del nuevo orden colonial.

Con todo ello no queremos decir que nos inclinamos hacia una defensa de Yanhuitlan o que los de Tecomatlan tenían plena razón, sino que en algunos casos es necesario tamizar el papel que la reorganización española jugó en la Mixteca. Pensamos que ciertos esquemas de dominio originados antes de la conquista debieron haber perdurado tras la implementación del régimen colonial.

Efectivamente, varios ñu y yuhuitayu estaban colocados en una posición subordinada tras la conquista española, como fue el caso del pueblo de Nunaha o Coxcaltepec, pero desconocemos si esta situación tenía antecedentes en la antigua organización indígena. ${ }^{32}$

31 Terraciano: The Mixtecs of Colonial Oaxaca..., pág. 129.

32 Hermann Lejarazu, Manuel A.: Códice Muro. Un documento colonial mixteco, Secretaría de Asuntos Indígenas, Gobierno del estado de Oaxaca, Oaxaca, 2003. 
Desde nuestra perspectiva, se requieren mayores investigaciones dedicadas a la reorganización política, territorial y jurídica que se implementó tras la llegada de los españoles. El caso de la separación de Tecomatlan del pueblo de Yanhuitlan, es sólo uno de los numerosos litigios que se suscitaron entre cabeceras y sujetos a lo largo de los tres siglos de vida virreinal.

La lucha separatista del pueblo de Tecomatlan no fue efectivamente una mera rebelión que aprovechó la reorganización española para buscar las mismas prerrogativas que tenía la cabecera, sino que existía un conflicto de fondo entre las antiguas costumbres que en algunos casos convenía mantener, y el nuevo orden que trajo consigo el régimen colonial con todas sus implicaciones.

Recibido el 6 de noviembre de 2007 Aceptado el 21 de febrero de 2008 